\title{
INTEGRAÇÃO CONCEPTUAL NA DESCRIÇÃO DE FENÔMENOS GRAMATICAIS DO PORTUGUÊS
}

\author{
Antônio Suárez ABREU*
}

- RESUMO: A Gramática funcional tem atualmente grande aceitação nos meios linguísticos, principalmente por ser capaz de esclarecer a motivação de fatos gramaticais na construção de um texto. A partir dela, deixa-se a tradição de estudar a gramática pela gramática. Pronomes demonstrativos, por exemplo, passam a ser vistos como ferramentas eficazes de coesão textual, retomando anaforicamente termos de orações anteriores. Essa tarefa, contudo, acaba deixando pelo caminho um rastro infindável de "caixas pretas". Como explicar a origem do funcionamento anafórico dos demonstrativos, se eles servem originalmente, na língua falada, para apontar coisas ou pessoas em relação à posição espacial dos interlocutores? O objetivo deste trabalho é mostrar que a Linguística Cognitiva surge justamente como uma opção de abertura dessas caixas pretas. No presente artigo, escolhi um de seus tópicos, a teoria da integração conceptual (blending) para defender essa possibilidade. Nessa tarefa, achei necessário, em primeiro lugar, integrar o modelo cognitivista dentro da Teoria da Complexidade, de acordo com Bybee (2010) e Castilho (2009), que defendem a linguagem humana como um sistema adaptativo complexo. Depois disso, faço uma breve descrição atualizada da teoria da integração conceptual e proponho sua aplicação a alguns fatos gramaticais da língua portuguesa, no nível morfológico e sintático.

- PALAVRAS-CHAVES: Integração conceptual. Blending. Complexidade. Gramática do português.

\section{Introdução}

Ao propor esse tema como colaboração para o "Projeto de Pesquisa Gramática do Português" ${ }^{1}$, tinha por objetivo demonstrar como o modelo da integração conceptual ou blending, desenvolvido inicialmente por Fauconnier eTurner (2002) e revisto por Bache (2005) e Hougaard (2005), pode ser utilizado para descrever fenômenos do português em seus vários níveis de análise e, além disso, ser utilizado também como recurso didático para o ensino dessa língua. Mas, tendo entrado em contato com inúmeros trabalhos sobre complexidade e sistemas complexos, tanto na área teórica geral, como os de Mitchell (2009) e Johnson (2009), quanto na área mais específica dos estudos da linguagem, como os realizados na Universidade de

* UNESP - Universidade Estadual Paulista. Faculdade de Ciências e Letras - Departamento de Lingüística. Araraquara - SP - Brasil. 14800-901 - tom_abreu@uol.com.br

1 O projeto de pesquisa "Gramática do Português" é desenvolvido no Ibilce, da UNESP de São José do Rio Preto, sob a direção do Prof. Dr. Roberto Camacho. 
Santa fé, nos EUA, por Ellis e Larsen-Freeman (2009), o de Bybee (2010) e alguns outros pioneiros em português, como os de Castilho (2009) e Paiva e Nascimento (2009), cheguei à conclusão de que se impunha, primeiramente, a tarefa de mostrar a relação entre alguns temas cognitivistas (entre eles o da integração conceptual) e a visão da linguagem como um sistema adaptativo complexo, tarefa que, segundo Bybee (2010), oferece a vantagem de se poder trabalhar tanto em descrições sincrônicas quanto em diacrônicas:

Uma vantagem da abordagem dos sistemas adaptativos complexos é que os processos cognitivos propostos para uso no processamento da linguagem são os mesmos processos que conduzem à mudança. Consequentemente, as explicações sobre as dimensões sincrônica e diacrônica ficam unidas. (BYBEE, 2010, p.32). ${ }^{2}$

\section{Algumas palavras sobre complexidade e sistemas complexos}

Eventos complexos são fenômenos que emergem produzindo desordem, sem necessidade de nenhuma "mão invisível" para isso e, em seguida, voltam a uma nova ordem. Um exemplo clássico é um engarrafamento de trânsito por excesso de veículos. Surge do nada e também do nada deixa de existir. Essa característica ordem $\rightarrow$ desordem $\rightarrow$ ordem é, portanto, característica básica da complexidade. Sistemas complexos obedecem ao mesmo princípio. A bolsa de valores, o tráfego aéreo e o corpo humano são sistemas complexos. Uma de suas características básicas é a adaptabilidade. No caso do corpo humano, nossas mãos foram feitas para pegar coisas, mas podemos adaptá-las para tocar piano; nossos pés foram feitos para caminhar, mas podemos adaptá-los para jogar futebol.

\section{Complexidade e teoria do caos}

Um olhar mais detalhado para o que chamamos de desordem nos levará a rebatizá-la de caos. Embora, dentro do senso comum, ambos esses conceitos sejam equivalentes, em sua origem grega e também em seu emprego atual dentro das ciências exatas, o caos possui características bem diferentes de uma pura desordem. Desordem, em sentido estrito, é aquilo que acontece, por exemplo, quando acumulamos a louça do almoço àquela usada no café da manhã sobre a pia da cozinha. Em nenhum momento, por si própria, essa louça suja vai transformar-se em limpa e guardar-se no armário. A menos que estejamos assistindo a um filme da série Harry Potter, em que um personagem utiliza, para isso, sua varinha mágica.

2 No original: "One advantage of the complex adaptive systems approach is that the cognitive processes proposed for use in processing language are the same processes that lead to change. Thus explanation on the synchronic and diachronic dimensions is united." 
O conceito de caos assemelha-se mais a uma mesa de carpinteiro. Temos lá pedaços de madeira, serra, lixas, pregos, martelo, esquadro, tudo numa aparente desordem. Mas o carpinteiro, ao fazer uma cadeira, sabe que instrumentos vai usar e em que sequência vai usá-los para trabalhar a madeira e fazer surgir o móvel que ele projetou. Caos seria, nessa nova maneira de pensar, uma coleção de "prompts" à espera de instruções de mudança. Mas de onde vêm essas instruções? No caso da mesa de carpinteiro, vêm da ideia, do projeto de cadeira que ele tem na cabeça. Vamos chamar essas instruções, esses apelos à mudança de atratores, termo cunhado por Edward Lorenz, na década de 60 do século passado, para referir-se a motivações em direção às quais um sistema dinâmico evolui, como ocorre, por exemplo, com as condições meteorológicas. Um outro exemplo comparativo, sugerido por Fleischer (2009), são os movimentos de uma bandeira agitada pelo vento. Não se trata, segundo ele, de um movimento desordenado, mas caótico, induzido por dois atratores: a gravidade, que é constante, e o vento, que varia em intensidade e direção. Como observadores, sabemos que não é possível determinar exatamente como acontecerão as alterações de posição da bandeira, mas sabemos, com toda a certeza, que ela não se moverá contra o vento ou que, cessado o vento, ela não se moverá para o alto, em direção contrária à atração da gravidade.

\section{Atratores linguísticos}

Bybee (2010) compara a estrutura das línguas humanas a dunas que, embora apresentem uma regularidade aparente em suas formas, estão em constante mudança (ordem $\rightarrow$ caos $\rightarrow$ ordem $\rightarrow$ caos....). Logo em seguida, vêa conveniência da aplicação dessa imagem a partir da ideia de adaptabilidade e variação gradual:

A primeira razão para ver a linguagem como um sistema adaptativo complexo, ou seja, como algo mais parecido com dunas de areia do que com uma estrutura planejada, como um edifício, é que a linguagem exibe uma grande quantidade de variação e de mudança gradativa. (BYBEE, 2010, p.69). ${ }^{3}$

No último capítulo, depois de definir o termo atrator ("Na literatura a respeito dos sistemas adaptativos complexos, atrator é o nome dado ao caminho seguido por um sistema dinâmico" (BYBEE, 2010, p.198, tradução nossa $\left.{ }^{4}\right)^{5}$ faz um esforço para elencar quais seriam os atratores da linguagem humana.Entre eles, relaciona

3 No original: "The primary reason for viewing language as a complex adaptive system, that is, as being more like sand dunes than like a planned structure, such as a building, is that language exhibits a great deal of variation and gradience."

4 A tradução deste texto e de todos os demais são de minha autoria.

5 No original: "In the literature on complex adaptive systems, 'atractor' is the name given to the path that a dynamic system takes." 
alguns bem gerais como: fatores sociais e culturais, inferência pragmática e outros mais específicos, como a lei da contiguidade, chunking ${ }^{6}$ e categorização.

A meu ver, podemos dividir, de modo aproximado, os atratores em gerais e específicos. Entre os gerais, podemos relacionar:

- Sentido;

- Economia;

- Tipologia da língua;

- Fatores culturais e sociais;

- Contiguidade;

- Contexto e inferência pragmática.

Entre os específicos:

- Corporificação;

- Esquemas de imagem;

- Integração conceptual ou blending,

\section{Sentido e economia}

O sentido é o principal atrator. Afinal, a função básica da linguagem humana é a comunicação,e isso não se faz na ausência de sentido. Em tensão dialética com o sentido, encontra-se o atrator geral da economia, também chamado de lei de Zipf, segundo a qual, em todas as línguas do mundo, as palavras de uso mais frequente serão sempre as menores. Exemplos disso são os pronomes pessoais e as preposições. É esse princípio atrator que explica reduções como as de fotografia para foto, de motocicleta para moto e de você para cê. Contudo, em uma casa em que exista uma Luciana e uma Lucimar, ambas não podem ser chamadas de Lu, uma vez que essa solução entraria em conflito com o primeiro e mais importante atrator, o sentido. Uma possibilidade é que uma seja chamada de Ana e a outra de Mar. De acordo com Bybee (2010), existe sempre uma espécie de competição entre falante e ouvinte em termos de economia e manutenção do sentido. O primeiro quer fazer o menor esforço possível e, por isso, tende a reduzir o que diz; o segundo deseja que as reduções do seu interlocutor não o prejudiquem em identificar itens lexicais e construções. Diz a autora que:

Chunking, de acordo com Bybee (2010, p.7), é "[...] o processo pelo qual sequências de unidades que são usadas juntas coerem para formar unidades mais complexas." No original: "Chunking is the process by which sequences of units that are used together cohere to form more complex units." 
Se o falante julga as unidades de uma sequência acessíveis ao interlocutor, então pode ser permitida a ocorrência de uma redução e coarticulação; mas se essas unidades são menos acessíveis, no julgamento do falante, então elas são articuladas com mais cuidado. (BYBEE, 2010, p.36).?

Alterações fonéticas, muitas vezes, dependem da manutenção do sentido. É comum, por exemplo, políticos e economistas pronunciarem, em entrevistas na televisão, a palavra subsídio com som de $\mathbf{z}$ (subzídio), mas ninguém pronuncia subsolo ou subseção como subzolo ou subzeção. O motivo é a barreira do sentido. Como não existe a palavra sídio, pode-se pronunciar subzídio sem problemas, mas, como existem as palavras solo e seção, a sonorização do s é sustada.

Vejamos outro exemplo da relação da fonética e sentido nas seguintes derivações:

$$
\begin{aligned}
& \text { pedra }+ \text { inha }=\text { pedrinha } \\
& \text { bola }+ \text { inha }=\text { bolinha } \\
& \text { porta }+ \text { inha }=\text { portinha }
\end{aligned}
$$

Em todos esses casos, as palavras derivadas ${ }^{8}$ conservam abertas as vogais


portinha. O mesmo não acontece, porém, nas seguintes derivações:

$$
\begin{aligned}
& \text { pedra }+ \text { ada }=\text { pedrada } \\
& \text { bola }+ \text { ada }=\text { bolada } \\
& \text { porta }+ \text { ão }=\text { portão }
\end{aligned}
$$

Em todos esses casos, nas palavras derivadas, as vogais que eram tônicas na palavra primitiva sofrem um levantamento: pedra / pedrada; bola / bolada; porta / portão.

Essa diferença se explica porque a vogal tônica marca a identidade significativa de uma palavra (corte é diferente de corte, por exemplo) e, nos casos de derivação com sufixo inha, essa identificação é mantida. Afinal de contas, uma pedrinha ainda é uma pedra, uma bolinha ainda é uma bola e uma portinha ainda é uma porta. O contrário acontece com as outras derivações: uma pedrada

\footnotetext{
7 No original: "If the speaker judges the units of the utterance to be highly accessible to the listener, then articulatory reduction and co-articulation are allowed to occur; but if the units are less accessible in the speaker's judgement, then they are articulated more carefully."

8 Pelo menos no dialeto paulista.
} 
não é mais uma pedra, uma bolada não é mais uma bola e um portão não é mais uma porta. Tanto é verdade que podemos utilizar essa última palavra no diminutivo: portãozinho.

\section{Tipologia da língua}

Outro atrator geral é a própria tipologia da língua. Um exemplo: como nos grupos consonantais em português, a segunda consoante tende sempre a ser um r ou um l, como em sem-pre e cla-ro, quando surge uma segunda consoante diferente, esse grupo é desfeito, como acontece com a palavra pneu, que, embora seja escrita dessa maneira, é pronunciada peneu independente do nível social do falante. Castilho (2010, p.51, grifo do autor) nos fala que:

Observa-se desde o latim vulgar uma tendência à abertura das sílabas. O português deu continuidade a essa tendência, tendo adotado duas soluções: (i) o PB omite a consoante travadora; cf.os menino por os meninos, fala por falar, (ii) o PE agrega uma vogal paragógica: cf. falári por falar, comêri por comer etc.

De fato, mesmo num registro social alto, em conversa informal, tanto o $r$ do infinitivo quanto outros erres finais desaparecem no português do Brasil, dando origem a frases, como:

Você qué viajá e i na Disney?

Em vez de:

Você quer viajar e ir na Disney?

Um fato interessante é que, com o verbo vir,essa forma de destravar a sílaba, além de eliminar o $\mathbf{r}$, nasaliza a vogal $\mathbf{i}$, produzindo vim(=vĩ) como em:

Elas querem vim em casa ainda este mês.

Ora, de onde vem essa forma vim, representando o infinitivo? Bem, ao eliminar o $\mathbf{r}$ do infinitivo do verbo vir, o resultado é vi, que é homônimo da primeira pessoa do perfeito do indicativo do verbo ver. Mas, como o verbo pretendido é vir e não ver, os falantes do português brasileiro "adaptam", imediatamente, em situação de uso, a forma vi à forma do verbo vir nessa mesma primeira pessoa do perfeito do indicativo, que é vim (eu vim, tu vieste, ele veio). Resolvido o problema! Afinal, na pronúncia, a sílaba fica destravada, ou seja, não é mais travada por consoante, pois termina por uma vogal, uma vogal nasal: [vĩ]. 


\section{Fatores culturais e sociais}

A cultura da comunidade que fala uma determinada língua é um forte atrator linguístico. É preciso levar em conta também o aspecto histórico e até mesmo diacrônico dessa língua. É comum, mesmo no momento presente, utilizar metáforas vinculadas a uma época em que o transporte, em terra, era feito por tração animal e, no mar, por navegação à vela ou a vapor:

O castigo vem a cavalo.

Pode tirar o cavalo da chuva.

Aquele seu amigo é uma mula.

Esse seu projeto vai indo de vento em popa.

O novo shopping vai indo a todo vapor.

Em inglês, para dizer que alguém está empenhando todo o esforço possível em realizar uma tarefa, é possível dizer algo como:

He is pulling out all the stops in his new job.

A expressão to pull out all the stops está ligada ao uso do órgão das igrejas inglesas e americanas. Stops, como substantivo, significa também os registros do órgão, aqueles botões que, uma vez puxados, liberam o sopro do ar para aumentar o volume do instrumento. Ora, se puxarmos todos os registros (stops), o volume do órgão atinge seu grau máximo. Daí a metáfora do esforço máximo contido na expressão idiomática to pull out all the stops.

Outro caso interessante provém do fato que, na Idade Média, pequenos animais, como coelhos e leitões, eram vendidos vivos nas feiras itinerantes que corriam de cidade em cidade e eram acondicionados em sacos de pano amarrados com um cordel. Consta que, de vez em quando, diante de um comprador distraído, um feirante de má fé punha, em vez do animal adquirido, um dos muitos gatos que perambulavam pela feira, em busca de alimento. Desse fato, resultou, em português, a expressão comprar gato por lebre, que significa ser enganado e, em inglês, let the cat out of the bag, que significa revelar um segredo.

Outro fato cultural interessante está na categorização das coisas como contáveis e não contáveis. Em português, por exemplo, informação e móvel são vistos como contáveis e podemos, portanto, dizer:

Preciso de duas informações.

Preciso vender esses móveis. 
Em inglês, não são contáveis e, por isso, temos de usar um classificador partitivo antes dessas palavras:

I need two pieces of information.

I need to sell those pieces of furniture.

Quanto aos fatores sociais, basta que nos lembremos de que há variantes prestigiadas e estigmatizadas em uma língua. Dizer, numa conversa informal, como vimos há pouco: Quero comprá um carro novo até o fim do ano, destravando a sílaba ar de comprar com eliminação do $\mathbf{r}$, é bastante aceitável. Dizer, contudo: Os menino já foram deitá, omitindo o $\mathbf{s}$ de meninos, é altamente estigmatizado, uma vez que o $\mathbf{s}$ (ao contrário do r) veicula uma marca morfológica, a marca morfológica de plural. Deixar de pronunciar o $\mathbf{r}$ em deitar tem apenas consequência fonética, mas deixar de pronunciar o $\mathbf{s}$ em meninos tem consequência morfológica e indica que o falante "não sabe fazer concordância".

\section{Contiguidade}

A contiguidade está relacionada aos princípios da associação de sensações e ideias, cuja origem recua até Platão e Aristóteles. Segundo a chamada lei da contiguidade, postulada por Aristóteles, ${ }^{9}$ coisas ou eventos que ocorrem próximos uns dos outros, tanto no espaço quanto no tempo, tendem a ligar-se dentro da mente do observador. Se você pensa em café, certamente pensará também em xícara. Se você pensa em casamento, pensará também em vestido de noiva e em lua-de-mel. Por meio da contiguidade, associada à lei da frequência, segundo a qual a quantidade de vezes em que dois objetos ou eventos se encontram ligados influi na força dessa associação, é que somos capazes de decorar poemas, orações e partituras musicais.

Um exemplo clássico do efeito da contiguidade é a origem da palavra piano, instrumento criado em 1711, na Itália, por Bartolomeo Cristofori, com o nome de pianoforte. Esse nome original referia-se ao avanço do novo instrumento em relação ao cravo, que tinha suas cordas "beliscadas" por palhetas acionadas por teclas e, por isso, não tinha variação de intensidade. Os sons, embora variassem quanto à altura das notas, mantinham sempre o mesmo volume. Como no pianoforte as cordas eram percutidas por meio de martelos acionados pelas teclas, o instrumentista podia controlar também a intensidade, tocando as notas com menor força ou volume (piano) ou com maior força ou volume (forte). Com o tempo, dada a contiguidade entre piano e forte em pianoforte, por razões de economia, o nome do novo instrumento foi reduzido simplesmente para piano,

Para mais informações, consulte Boeree em <http//:webspace.ship.edu/egboer/psychbeginnings.html>. 
perdendo essa palavra o sentido original de oposição fraco / forte.É esse mesmo processo que está na origem de várias palavras do português como pêssego, por exemplo. Pêssego, em sua origem, é o adjetivo pérsico. O nome primitivo dessa fruta era fructu persicu (= fruto da Pérsia). Em função da contiguidade e da economia, o nome composto ficou reduzido apenas ao adjetivo que, sujeito às leis fonéticas da assimilação do $r$ ao $s$ e da sonorização da consoante intervocálica c em $\mathbf{g}$, resultou na forma atual pêssego. É a contiguidade que explica também reduções sincrônicas feitas por economia, como: fotografia $\rightarrow$ foto; motocicleta $\rightarrow$ moto; telefone celular $\rightarrow$ celular.

Fazendo uso da sugestão de Bybee (2010) de aplicação da complexidade à diacronia, podemos dizer que foi também o atrator contiguidade, dentro do paradigma do português, que fez aparecer a nasalidade no advérbio sim. Essa palavra vem do latim sic e, portanto, não haveria ambiente fonético para o surgimento de nasalidade, mas não, o seu oposto paradigmático apresenta nasalidade, e isso funcionou como atrator de contiguidade, por contraste, para o surgimento da nasalidade em sim.

\section{Contexto e inferência pragmática}

Outro importante atrator linguístico é o contexto, que propicia inferências pragmáticas, diferentes sentidos atribuídos por um interlocutor a um texto. Se alguém entra em um bar e pede um copo de leite esse substantivo terá um sentido bem diferente de uma outra situação em que um indivíduo entra em uma floricultura e faz o mesmo pedido. A interpretação de um aviso que diz cuidado, cães bravos difere, pelo contexto, de outro que diz cuidado, crianças.

Contexto e inferência pragmática dependem também da cultura. Coulson (2001) nos revela um caso curioso a esse respeito. A Gerber Products Company, empresa especializada em alimentação infantil, costuma dispor nas gôndolas dos supermercados norte-americanos recipientes de comida infantil pronta para o uso, com a figura sorridente de uma criança de oito meses estampada nos rótulos, sob o qual se encontra a expressão baby food. Quando esse tipo de alimento começou a ser exportado para países africanos com altas taxas de mortalidade infantil e com a maioria de população analfabeta, o efeito foi catastrófico, pois os habitantes dessas localidades tinham por costume associar o conteúdo do recipiente à figura exposta no rótulo e, em consequência, inferiam pragmaticamente que "os americanos capitalistas estariam reprocessando suas crianças mortas como alimento". Para evitar o problema, a Gerber mudou o rótulo dos vidrinhos por outro, em que aparecia a figura de uma mãe alimentando uma criança com uma colher. 


\section{Corporificação e esquemas de imagem}

Contrariamente à tradição cartesiana, a moderna neurociência nega haver uma dicotomia corpo/mente. Segundo Gibbs Jr. (2005, p.9):

A linguagem humana e o pensamento emergem de modelos recorrentes de atividades corporificadas que influenciam o desenvolvimento do comportamento inteligente. Não devemos assumir a cognição como algo puramente interno, simbólico, computacional e fora do corpo, mas procurar os meios completos e detalhados pelos quais a linguagem e pensamento estão inextrincavelmente formatados pela ação corporificada. ${ }^{10}$

De fato, basta pensar nas expressões diárias em que usamos partes do nosso corpo como: Em que pé está aquele nosso acordo? Ou Ele errou a mão naquele castigo que impôs ao filho. Ou ainda em expressões em que usamos sentidos e ações do nosso corpo, como em: A ausência de uma autoridade responsável não está me cheirando bem. Ou $\mathrm{O}$ piloto teve de abortar a decolagem da aeronave.

Outro importante aspecto ligado a esse atrator é o movimento. Como diz também Gibbs Jr. (2005, p.27):

Movimento é fundamental em termos de como nós concebemos a relação entre nós mesmos e nossos corpos. Nós não sentimos experiências subjetivas como estados mentais específicos, mas sensações de nossos corpos em ação. ${ }^{11}$

Foi a partir da ideia de movimento que a linguística cognitiva começou a trabalhar com os chamados esquemas de imagem. Segundo Lakoff e Johnson (1999), esses esquemas são padrões estruturais recorrentes em nossa experiência sensório-motora, que, quase sempre, servem para estruturar conceitos complexos.

Do fato de que, para andar, temos de manter nossa posição ortostática, surge o esquema de EQUILÍBRIO ${ }^{22}$ (BALANCE, em inglês). Do fato de que nos movemos, nasce o esquema de PERCURSO, composto por três elementos: ORIGEM, TRAJETO e META (SOURCE-PATH-GOAL, em inglês). Quando, em

10 No original: "Human language and thought emerge from recurring patterns of embodied activity that constrain ongoing intelligent behavior. We must not assume cognition to be purely internal, symbolic, computational, and disembodied, but seek out the gross and detailed waist ha language and thought are inextricably shaped by embodied action."

11 No original: "Movement is central to how we conceive of the relation between ourselves and our bodies. We do not feel subjective experiences to be specific brain states, but sensations of our bodies in action."

12 Por convenção, os nomes dos esquemas de imagem são sempre transcritos em letras maiúsculas. 
percurso, podemos nos encontrar com alguém ou com algo, temos, então, o esquema de CONTATO (CONTACT, em inglês). Podemos enfrentar obstáculos como uma porta fechada, o que configura o esquema de BLOQUEIO (BLOCKAGE, em inglês). Podemos aplicar a força do nosso braço e abrir a porta. Temos, então, o esquema de DINÂMICA DE FORÇAS (FORCE-DYNAMICS), por meio do qual exercemos controle sobre o obstáculo. Podemos entrar em um edifício ou em um automóvel; podemos pôr alguma coisa dentro dos nossos bolsos. Temos, então, o esquema de CONTAINER. Todos esses esquemas são usados costumeiramente para metaforizar eventos abstratos. Exemplos:

Agora sim, estou no caminho certo nesta pesquisa.

Nosso relacionamento chegou a uma encruzilhada.

Vamos pôr de lado, por enquanto, esse problema.

Não vou bater de frente contra essa ideia.

Isso não consegue entrar na minha cabeça!

\section{Integração conceptual ou blending}

Finalmente, o atrator objeto deste trabalho. Proposto por Fauconnier e Turner (2002), esse tema tem sido objeto de variados estudos teóricos e práticos, críticas e aperfeiçoamentos. Segundo seus autores, o escopo desse atrator não se limita à linguagem. É parte essencial do sistema cognitivo dos seres humanos, atuando nas mais diversas situações. Dizem eles que:

Blending não é alguma coisa que fazemos em acréscimo a viver no mundo; é a nossa maneira de viver no mundo. Viver no universo humano é "viver dentro do blend", ou melhor, viver em muitos blends coordenados. Até mesmo lembrando o mundo e nossa atividade dentro dele parece depender da existência do tipo de blends que desenvolvemos a partir dos três anos de idade. Nós conservamos apenas lembranças desorganizadas e fragmentadas da época antes dessa etapa.

A história não é diferente em relação a aprender números, escrever, história, modelos sociais, e qualquer outra integração, exceto que depois de três anos de idade nós conseguimos lembrar o esforço pelo qual nós passamos para adquirir o blend. Nós sabemos quando nos vemos escrevendo que nós estamos vivendo diretamente dentro blend e não podemos escapar dele, mas muitos de nós podemos também nos lembrar da época quando a escrita eram apenas marcas em uma página. [...] Tocar piano, entender sacramentos, interpretar ações sociais adultas, 
e utilizar números complexos tudo mostra esse modelo. É o modelo universal do aprendizado cultural humano. (FAUCONNIER; TURNER, 2002, p.390-391). ${ }^{13}$

As integrações conceptuais mais comuns e primitivas da natureza humana são as que a moderna neurociência chama de binding, termo utilizado para descrever a natureza combinatória da percepção holística ou representação mental unificada. ${ }^{14}$ Quando vemos um objeto qualquer, uma xícara, por exemplo, diversas regiões do nosso cérebro são ativadas, cada uma de suas regiões processando uma parte do objeto, como formato, cor, textura etc. Nosso próprio cérebro, portanto, integra conceptualmente essas várias características e no-las apresenta à consciência numa única janela. Como diz Bache (2005, p.1.619): "Binding, portanto, refere-se à unificação de inputs sensoriais parciais e separados processados em diferentes regiões do cérebro." ${ }^{15}$ Isso nos permite, inclusive, a capacidade de categorização, pois, ao vermos uma outra xícara qualquer, mesmo que tenha dimensões e cores diferentes, nosso cérebro a integra, holisticamente, dentro da mesma categoria de xícara.

Causa e efeito e metonímia estão entre outras integrações conceptuais primitivas dentro do cérebro humano. Ambas se articulam com o atrator contiguidade. Causa e efeito, com contiguidade no tempo (dois momentos próximos) e metonímia, com contiguidade no espaço (parte e todo). Qualquer um de nós é capaz de integrar nuvens escuras no céu, ruído de trovões e o aumento da força do vento à proximidade de uma tempestade. Integração causa e efeito! Qualquer um de nós, sentado à frente de outra pessoa em uma mesa de bar, vendo apenas parte de seu tronco e braços por sobre a mesa, é capaz de inferir, por integração conceptual, que ela se acha inteira do outro lado. Integração metonímica parte-todo! Bache (2005) batiza esse primeiro nível de integração conceptual de Blending de primeira ordem (first-order blending) e afirma que compartilhamos esse primeiro nível com outros primatas e que ele acontece numa etapa ainda pré-linguística:

13 No original: "Blending is not something we do in addition to living in the world; it is our means of living in the word. Living in the human world is "living in the blend", or rather, living in many coordinated blends. Even remembering the world and our activity in it seems to depend upon the existence of the kind of blends threeyear-old as have developed. We retain only fragmentary and an unorganized conscious memories from before that stage.

The story is no different for the learning of numbers, writing, history, social patterns, of any other integration, except that after about three years of age we can remember the work we went through to acquire the blend. We know when we look at writing that we are living directly in the blend and cannot escape it, but most of us can also remember the time when writing was only marks on a page. [...] Playing the piano, understanding sacraments, interpreting adult social action, and using complex numbers all show this pattern. It is the pattern of human cultural learning worldwide."

14 Para mais informações, veja Bache (2005)

15 No original: "Binding thus refers to the unification of the separate and partial sensory input processed in different brain regions." 
O blending de primeira ordem é automático, inconsciente e inevitável em um cérebro humano normal. Trata-se de uma habilidade básica que humanos obviamente compartilham com outros primatas (julgando a partir das observações feitas por Tomasello, 1999: 7, 10, 16ff), embora tenha provavelmente se desenvolvido diferentemente em diferentes espécies favorecendo a diferentes propósitos específicos dessas espécies. (BACHE, 2005, p.1.621). ${ }^{16}$

É importante salientar que o blending de primeira ordem é, ao menos em princípio, independente da linguagem. Mesmo que não tivéssemos linguagem, nós ainda assim seríamos capazes do blending de primeira ordem, tal quais outros mamíferos e primatas. (BACHE, 2005, p.1.621, grifo do autor). ${ }^{17}$

O blending de segunda ordem, por outro lado, configura operações de integração conceptual em operações tipicamente humanas fundamentadas nos resultados do blending de primeira ordem. A primeira delas consiste na referenciação, ou seja, a integração conceptual de determinadas sequências sonoras (palavras) às nossas percepções e conceptualizações do mundo, o que permite à espécie humana a capacidade única de poder referenciar "em ausência". De fato, ao contrário dos chimpanzés e das abelhas, podemos falar de coisas e de lugares que não estão presentes no contexto físico de uma interação comunicativa. Estando na cidade de São Paulo, por exemplo, posso dizer coisas como No ano passado, em Paris, vi a Vênus de Milo no Museu do Louvre. Ainda dentro do blending de segunda ordem, fazemos a integração de histórias abstratas com estruturas gramaticais produzindo construções gramaticais. Da narrativa abstrata de um agente que provoca o movimento de um objeto em uma determinada direção, criamos estruturas gramaticais do tipo: SNV SN Sprep, como em:

Rodrigo jogou o guardanapo no cesto de papel.

$\begin{array}{llll}\text { SN } & \text { V } & \text { SN } & \text { Sprep }\end{array}$

A partir desse tipo de projeção, podemos criar também metáforas gramaticais como:

Rodrigo jogou toda a culpa no coitado do jardineiro.

$\begin{array}{llll}\text { SN } & \text { V SN }\end{array}$

16 No original: "First-order blending is automatic, unconscious and inevitably in a normal human brain. It is a basic skill which humans obviously share with other primates (judging from the observations made by Tomasello, 1999: 7, 10, 16ff), though it has probably developed differently in different species to suit different speciesspecific purposes."

17 No original: "It is important to note that first-order blending is, at least in principle, independent of language. Even if we did not have language, we would still be able to first-order blend, just like other mammals and primates." 
Como diz Bache (2005, p.1.622),

O que é importante notar nesse ponto é a combinação da cognição com a linguagem, i. e., nossa habilidade em associar estruturas narrativas particulares de histórias abstratas básicas, por um lado, com estruturas gramaticais abstratas particulares por outro (e vice-versa), o que resulta em exemplos de fato de causa-movimento. ${ }^{18}$

E, concluindo:

O blending de segunda ordem diz respeito crucialmente à própria relação entre a estrutura da linguagem e a mente humana e, enquanto tal, reflete diretamente a função significativa básica da linguagem. (BACHE, 2005, p.1.624). ${ }^{19}$

Finalmente, o blending de terceira ordem é responsável, além das metáforas gramaticais do dia a dia, por outras projeções criativas de várias ordens, tanto metafóricas como metonímicas. É por meio dessa ordem de blending que podemos construir frases como:

O 11 de setembro jogou um balde de água fria nas previsões de paz para o século XXI.

As revoltas populares nos países árabes atropelaram os setores de inteligência do Pentágono.

Segundo Bache (2005, p.1.624), " [...] nossa habilidade para usar tais blends construtivamente e criativamente faz do blending de terceira ordem uma poderosa e dinâmica habilidade, muito provavelmente não compartilhada por nenhuma outra espécie."20

\section{Desvendando o mecanismo da integração conceptual ou blending}

Não pretendo, neste artigo, percorrer todo o caminho realizado por Fauconnier e Turner (2002), na distinção dos vários tipos de integração conceptual por eles denominados de simplex network, mirror networks, simple-scope networks e

18 No original: "What is important to note at this point is the direct matching of cognition with language, i.e., our ability to associate particular narrative structures of basic abstract stories on the one hand with particular abstract grammatical structures on the other (an vice versa), which results in actual specific caused-motion examples.

19 No original: "second-order blending crucially concerns the very relationship between language structure and the human mind, and as such is directly reflects the basic semiological function of language."

20 No original: "Our ability to use such blends constructively and creatively makes third-order blending a dynamics and powerful cognitive skill, mostprobably not shared by any other species." 
double-scope networks. Caso necessário, explicarei alguns desses conceitos, quando da análise de dados do português. O que é relevante, neste momento, é explicitar como se dá, em nossa mente, o processo de integração conceptual, em termos gerais, para que possamos entender sua aplicação aos fatos que pretendo analisar.

Examinemos a seguinte frase: Minha mãe é uma rocha. Trata-se, é claro, de uma metáfora em que se projeta a ideia de rocha em minha mãe, para enfatizar que ela é forte, resistente. De acordo com a teoria clássica de Fauconnier e Turner (2002), temos dois inputs, um espaço genérico e um espaço blend, como mostra o desenho:

\section{Imagem 1 - Esquema blend.}

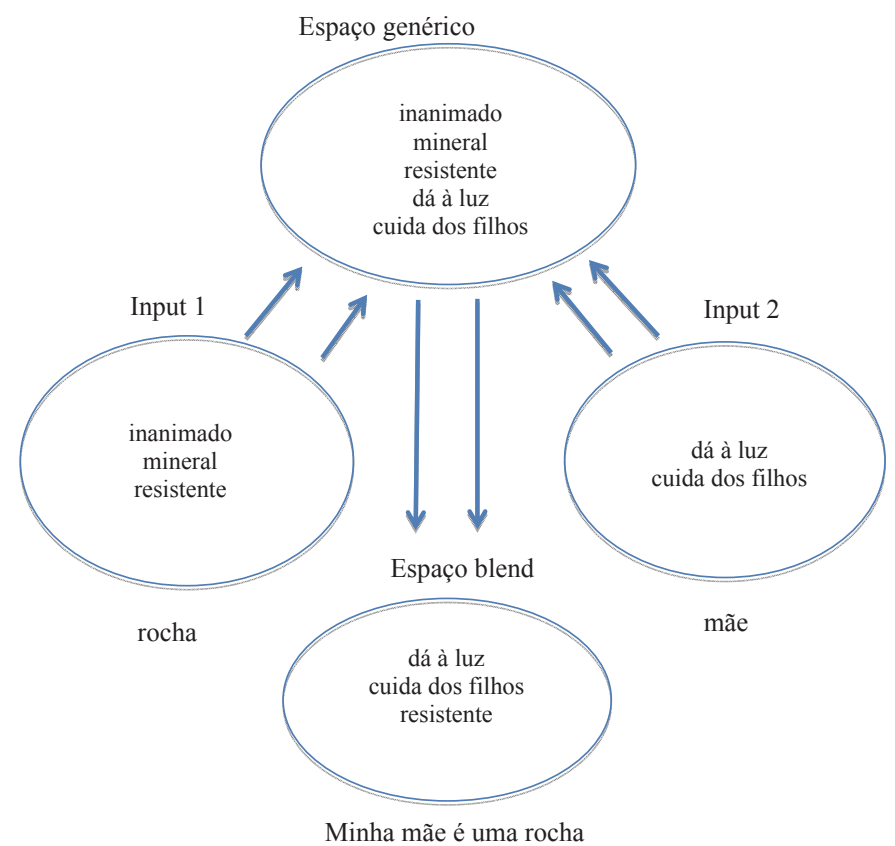

Fonte: Elaboração própria.

Para produzir essa frase, o falante integra conceptualmente a ideia de rocha à ideia de mãe. Mas, nem todos os elementos do frame ${ }^{21}$ de rocha são projetados no espaço blend. Elementos como inanimado e mineral são "desintegrados" nesse processo, de acordo com a proposta de Bache (2005) e Hougaard (2005).

21 Frame é o domínio semântico de uma palavra que contém elementos vinculados a ela. O frame de Natal, por exemplo, contém elementos como: Papai Noel, árvore de Natal, presentes, fraternidade etc. (ABREU, 2010). 
De fato, quando dizemos Minha mãe é uma rocha, não queremos dizer que ela é inanimada ou que tem natureza mineral, mas apenas que ela é uma mulher forte. Esse conceito de "desintegração", que prefiro chamar de "desabilitação", é crucial para entender a maioria dos processos de integração conceptual. Vejamos, a título de exemplo, as seguintes frases:

Meu carro anda gastando muito combustível.

Meu carro vive esquentando sem motivo aparente.

Temos dois tipos de adaptação por meio de integração conceptual. O frame do verbo andar contém elementos como locomoção a pé e duração continuada breve. $O$ do verbo viver contém elementos como atividade vital e duração continuada longa. Para que o verbo andar possa funcionar como verbo auxiliar de aspecto, foi mantido apenas o elemento duração continuada breve, tendo sido o elemento locomoção a pé "desintegrado" ou desabilitado. Para que o verbo viver possa funcionar como auxiliar de aspecto, foi mantido apenas o elemento duração continuada longa, e foi desativado o elemento atividade vital. $O$ mesmo acontece com os pronomes demonstrativos de que falo no resumo deste trabalho. Sua adaptação de indicador espacial para a função anafórica substitui a referência dêitica pela metalinguística (o termo da oração anterior) e desabilita o traço espacial do frame. No caso de aquele em função anafórica, o traço espaço é substituído pelo tempo, em frases como: Quando tinha cinco anos, viajei pela primeira vez ao exterior. Naquela idade não pude aproveitar muita coisa.

Essa característica de pôr em foco um elemento de um frame, desabilitando outros, faz parte do nosso dia a dia como seres humanos. Trata-se de um processo chamado Gestalt, por meio do qual elegemos, nas diversas situações por que passamos, um elemento como figura, deixando os outros como fundo. O exemplo clássico de Perls (1988) nos mostra um cidadão que foi a uma festa apenas com o objetivo de beber de graça. Entrando no recinto, onde há várias pessoas, móveis finos, quadros na parede, música ambiente, ele divisa, no fundo da sala, um garçom servindo uísque. Põe, então, em segundo plano todos os elementos da festa e para lá se dirige, recebe um copo de uísque com gelo que começa a degustá-lo. Pronto, ele fechou sua Gestalt! O que move a decisão de eleger um elemento como figura e desconsiderar os outros é, segundo o autor, o interesse. No exemplo dado, o interesse do convidado em beber. Podemos, de maneira "mais moderna", chamar esse interesse de atrator. Schmid (2011) resume muito bem esse ponto de vista, quando diz que:

O processo do blending conceptual projeta material conceptual selecionado de dois ou mais espaços mentais em um novo espaço blending (mesclado) e combina-o, reduzindo, desse modo, a 
Voltando aos exemplos linguísticos anteriores, podemos nos perguntar qual foi o atrator que levou os falantes do português a adaptarem os verbos andar e viver como auxiliares de aspecto? Podemos dizer que foi a necessidade de modular a duração de gastar combustível ou de esquentar. Outras vezes, o atrator pode ser a emoção, como acontece, por exemplo, com a formação do futuro na maioria das línguas do mundo. Diferentemente do presente ou do passado, que representam instâncias reais de tempo, o futuro é desconhecido, o que nos leva sempre a tentar fazer referência a ele de maneira emocional, envolvendo o desejo de que nos aconteçam apenas coisas boas e não más. Bybee $(2010$,$) nos$ diz que, na maioria das línguas do mundo, o tempo futuro é gramaticalizado com marcadores que indicam:

a) Movimento em direção a uma meta;

b) Desejo, volição;

c) Dever, obrigação.

Em inglês, podemos considerar formas de referenciar o futuro, como:

I am going to buy a new car.

I will win that girl.

I ought to have been there.

Em português:

Eu vou comprar um carro novo.

Eu conquistarei aquela garota.

Eu quero conquistar aquela garota.

Eu preciso estar lá. / Eu tenho de estar lá.

Mesmo a ideia de movimento, contida em ir em português ou em I am going to em inglês, tem ligação com emoção. Segundo Gibbs Jr. (2005, p.243-244),

A relação fundamental entre ação corporificada e emoção é captada pela ideia de que ser movido refere-se a sentir-se como estar em uma

22 No original: "The process of conceptual blending projects selected conceptual material from two or more mental spaces into a new blended space and merges it, thus reducing the conceptual complexity of the input and turning it into one holistically experienced conceptual Gestalt." 
posição diferente em relação a uma dada situação. A palavra emoção é derivada do latim "e" (fora) e "movere" (mover). A ênfase do movimento em emoção é um tema recorrente na literatura psicológica. ${ }^{23}$

Em Eu vou comprar um carro novo, o frame de ir contém, em seu núcleo duro, os elementos: locomoção e também subsequência. Afinal, o resultado de ir a algum lugar é subsequente à ação de ir. No processo de integração conceptual entre esse verbo e a categoria de tempo futuro, permanece apenas subsequência, sendo desabilitado o elemento locomoção. O mesmo ocorre em inglês com a expressão I am going to.

\title{
Alguns exemplos da aplicação da teoria da integração conceptual como procedimento de adaptação em português
}

A integração conceptual aliada à contiguidade é responsável por uma série de fenômenos gramaticais em português, em seus vários níveis: fonético, morfológico e sintático. Cumpre lembrar, inicialmente, que, no modelo da gramática cognitiva, não se faz a nítida distinção clássica entre esses níveis de análise. De acordo com Taylor (2003, p.30):

\begin{abstract}
A Gramática Cognitiva não leva em conta muitas das distinções feitas tradicionalmente pela teoria linguística. Por exemplo, a sintaxe (que estuda a estrutura interna dos sintagmas) e a morfologia (que estuda a estrutura interna das palavras) são tradicionalmente tratadas em componentes separados, ou módulos, de uma gramática. A distinção entre palavra e sintagma é certamente válida, em termos gerais. Apesar disso, os mesmos tipos de operação estão essencialmente envolvidos na união de pequenos componentes no interior de expressões complexas, sejam essas expressões complexas palavras ou sintagmas. ${ }^{24}$
\end{abstract}

No nível fonético / fonológico, uma palavra como você pode ser reduzida a cê, uma vez que, por contiguidade, o significado da palavra você fica integrado em cê. Funciona, também, nesse caso, o atrator economia, que leva o falante, com a conivência do seu interlocutor, a abreviar tanto quanto possível tudo

23 No original: "The fundamental relation between embodied action and emotion is captured by the idea that to "bee moved" refers to felling as if one is in a different position in regard to one's situation. The word "emotion" is derived from the Latin " $"$ " (out) and "movere" (to move). The emphasis on movement in emotion is a recurrent theme in the psychological literature."

24 No original: "Cognitive Grammar blurs many of the distinctions traditionally made in linguistic theory. For example, syntax (which studies the internal structure of phrases) and morphology (which studies the internal structure of words) are traditionally handled by separate components, or modules, of a grammar. The distinction between word and phrase is certainly a valid one, in general. Nevertheless, essentially the same kinds of operations are involved in the assembly of smaller components into internally complex expressions, whether the complex expression be words or phrases." 
aquilo que diz. O mesmo fenômeno acontece em relação a outras reduções de palavras como para / pra; quer / qué e ainda no uso de siglas, como USP, ONU, GPS etc.

No nível morfológico, são comuns, como vimos em seção anterior, reduções como:

$$
\begin{aligned}
& \text { telefone celular } \rightarrow \text { celular } \\
& \text { arremesso lateral } \rightarrow \text { lateral } \\
& \text { filme de curta metragem } \rightarrow \text { curta }
\end{aligned}
$$

Dois atratores criam condições para essa integração conceptual: economia e contiguidade. O sentido da expressão inteira fica integrado em uma só palavra, o que permite frases como:

Meu celular está sem sinal.

O jogador cobrou mal o lateral.

Aquele cineasta fez dois curtas e um longa no ano passado.

É importante ressaltar que, no processo de integração conceptual, o sentido da palavra ou das palavras resultantes tem apenas o significado do todo de que provieram, sendo desabilitado ou "desintegrado" seu significado individual original. Celular, por exemplo, significa originalmente relativo à célula, uma vez que telefone celular quer dizer, literalmente, um telefone cuja fonte de transmissão de voz são células ligadas a grandes antenas. Mas, em uma frase como Esqueci meu celular, celular significa apenas o todo de que essa palavra provém, por integração conceptual: telefone celular. Podemos entender melhor esse processo, analisando duas expressões comuns em nosso dia a dia: risco de vida $e$ pois não.

Risco de vida é uma redução da expressão risco de perder a vida, criada por um atrator social vinculado ao uso de eufemismos para tratar do tema da morte. Ora, reduzida essa expressão a risco de vida, o significado total é o único mantido, sendo desabilitado o sentido original da palavra vida (como é desabilitado o sentido de locomoção a pé em $\mathrm{Meu}$ carro anda dando problemas). Infelizmente, muitos jornalistas, por um absurdo excesso de zelo, acabam substituindo essa genuína expressão portuguesa por risco de morte.

Pois não, resposta comumente empregada em português com sentido positivo, está ligado ao hábito de o falante procurar atenuar o que diz, para preservar a sua face, em frases como: Você vai me ajudar nessa tarefa, não é verdade? Essa expressão acabou reduzida a não é e a né: Você vai me ajudar 
nessa tarefa,não é? / né? Trata-se de um atrator social. Antigamente, sobretudo em Portugal, era comum acrescentar a palavra pois antes do não, como nos exemplos:

Todo patriota deveria apostar pelo cavalo do visconde. Pois não é verdade, Sr. Afonso Maia? (Eça de Queirós)

Se virá o bispo à mais antiga e respeitável festividade de nossa igreja? Pois não há de vir heim? (Almeida Garret) ${ }^{25}$

Esse procedimento era empregado também em respostas como em:

— Você me faz esse favor?

- Pois não haverei de fazer?

Ora, todos esses grupos podiam ser reduzidos à expressão pois não:

Todo patriota deveria apostar pelo cavalo do visconde, pois não?

Se virá o bispo à mais antiga e respeitável festividade de nossa igreja, pois não?

- Você me faz esse favor?

- Pois não.

No caso da resposta, o sentido pragmático afirmativo do todo (pois não haverei de fazer?), por integração conceptual, acaba incorporado a pois não e o sentido negativo de não é desabilitado. Pois não, como resposta afirmativa a uma solicitação é, pois, o resultado da integração conceptual do significado de uma expressão mais longa, que significava afirmação por uma espécie de metáfora de polidez, e da desabilitação do sentido original de negação do não.

No nível sintático, o fato mais comum de integração conceptual, análogo ao que acabamos de ver no nível morfológico, é o da omissão de termos em uma oração que podem ser recuperados de uma oração anterior, como em:

Eu comprei dois quilos de açúcar. Minha irmã, três.

Em Minha irmã, três, acham-se integrados um verbo (comprar) e um pedaço de sintagma nominal (quilos de açúcar): Minha irmã comprou três quilos de açúcar.

25 Exemplos retirados do livro Corpus de Português, de Mark Davies e Michael Ferreira (2006). 
A palavra sim ou a simples repetição do verbo de uma oração anterior ou o uso do verbo ser são usados, em situação de discurso, para integrar conceptualmente (movidos pelo atrator economia) todo o conteúdo de uma frase anterior. Exemplo:

— Você levou três dias para fazer esse relatório?

- Sim / Levei / Foi.

Vejamos mais alguns casos de integração conceptual no nível sintático, envolvendo agora orações complexas, em frases como:

Ele agiu como se fosse o dono da casa.

Os americanos invadiram o Iraque, mas havia suspeitas de armas de destruição em massa.

Se você está com fome, tem presunto e queijo na geladeira.

Na primeira frase, houve a integração de um sentido condicional na oração comparativa que "compactou a condicional", provocando a gramaticalização de como se como uma locução conjuntiva de comparação. A forma reconstruída dessa frase seria algo como:

Ele agiu como [agiria] se fosse o dono da casa.

Na segunda frase, entra em ação o atrator inferência pragmática. A oração adversativa ganha um sentido causal, herdado de uma construção mais complexa, como:

Os americanos invadiram o Iraque, mas [invadiram porque] havia suspeitas de armas de destruição em massa.

Na terceira, a oração principal tem o valor pragmático de causa, pois integra o sentido de outra oração principal que fica implícita:

Se você está com fome, [pode matar sua fome / comer / alimentar-se, porque] tem presunto e queijo na geladeira.

\section{Integração conceptual e o caso das metáforas temporais}

É amplamente conhecido e divulgado em gramáticas e livros escolares que os tempos verbais podem ser empregados de forma "não literal". Nos anos 70, Weinrich (1973), em seu livro Le temps: le récit e le commentaire, ${ }^{26}$ fez uma

26 Tradução do alemão: Tempus - Besprochene und erzählte Welt. 
interessante análise funcionalista a respeito daquilo que ele chamou de metáforas temporais, o uso dos tempos do chamado mundo narrado (passado) no mundo comentado (presente e futuro), e o uso dos tempos do mundo comentado no mundo narrado. Segundo ele, o uso dos tempos do passado para referir-se a fatos presentes serviria para manifestar polidez ou incluir uma perspectiva hipotética ao que é dito; e o uso do presente e do futuro para referir-se a fatos passados, para dar mais visibilidade a um evento, tornando-o mais concreto.Exemplos do primeiro tipo de metáfora podem ser vistos no uso metafórico do futuro do pretérito em frases como:

Eu gostaria de ver aquela blusa da vitrine.

Eu poderia chegar mais tarde amanhã?

Petrobrás aumentaria a gasolina nos próximos meses.

Ministério Público teria apresentado denúncia ao Supremo já em 2006.

Nas duas primeiras, é nítida a intenção do falante em manifestar um desejo de forma polida, atenuada. Nas outras duas, a intenção de não se comprometer com o que diz. Um exemplo do segundo tipo de metáfora pode ser visto no trecho a seguir, comentando a necessidade de os franceses fabricarem mais munição, no início da Primeira Guerra Mundial, em 1914:

Logo se percebe que todas as previsões são ultrapassadas. Pouco mais de um mês após o início das hostilidades, o ministro francês da Guerra, Alexande Millerand, convoca os principais industriais e lhes comunica que, dentro de dois meses, faltará munição para os canhões franceses. Énecessário, pois, conseguir produzir 100000 projéteis por dia. Só a fábrica da Citroën recebe uma encomenda de um milhão de unidades. O Estado oferece financiamentos para aumentar o poderio das fábricas existentes e originar outras novas. Durante o verão de 1915 o objetivo previsto éatingido, com um aumento vertiginoso no ritmo de trabalho, na produtividade e nos lucros. Em Toulouse, uma fábrica de pólvora para canhões que antes da guerra tinha cem operários passa a 4000 em junho de 1914, sobe para 20000 um ano mais tarde, e no momento do armistício, em 1918, atinge 30000 operários. (ISNENGHI, 1995, p.42-43, grifo nosso).

Para relatar fatos ocorridos cem anos atrás, o autor utiliza tanto o presente (são, comunica, recebe) quanto o futuro do presente (faltará).

Até aqui, o modelo funcionalista explica, de modo competente, a função desses empregos metafóricos: polidez, atenuação, mais dramaticidade a eventos passados. Mas falta ainda explicar o que leva o falante ao uso figurado desses 
tempos verbais e não ao emprego de outras estratégias. É aqui que entra, a meu ver, o modelo cognitivista da integração conceptual.

O emprego canônico do futuro do pretérito é narrar um fato passado, mas futuro em relação a outro fato passado, como em:

O presidente americano chegou ontem às $8 \mathrm{~h}$ a Paris. Ao meio dia almoçaria com o presidente francês.

Veja que ambos os eventos já aconteceram no passado. O almoço com o presidente francês, contudo, é futuro em relação ao fato de o presidente americano ter chegado às 8h. A metáfora temporal que ocorre por motivos de polidez exemplifica-se, como já visto, em frases como:

Eu gostaria de ver aquela blusa da vitrine.

Eupoderia chegar mais tarde amanhã?

Minha tese é que esse emprego decorre de uma adaptação surgida por integração conceptual em construções condicionais como:

Se eu ganhasse na loteria, compraria um carro importado.

Nesse contexto, temos ainda um futuro do pretérito canônico, pois é preciso, primeiro, ganhar na loteria, para depois comprar o carro importado. Mas, por contiguidade, em relação à oração condicional, esse futuro do pretérito assume também os sentidos de condição e de hipótese,sentidos que são adaptados nas orações usadas como metáfora temporal. Querendo, podemos até mesmo "repor" orações condicionais junto a essas orações, dizendo:

Eu gostaria de ver aquela blusa da vitrine, se você quiser / puder mostrá-la.

Eu poderia chegar mais tarde amanhã? Se você permitir / concordar.

Dado esse caráter hipotético adquirido pelo futuro do pretérito na integração conceptual com orações condicionais, esse tempo pode, também, ser adaptado em outras orações em que o foco não é mais a polidez, mas a indicação de um baixo nível de evidencialidade, com objetivo de preservar a face do enunciador:

COPOM aumentaria amanhã a taxa de juros. 
Nessa outra adaptação, apenas o traço de hipótese é integrado. O sentido condicional é desabilitado ou "desintegrado". Prova disso é que não podemos "repor", num caso desses, uma oração condicional:

COPOM aumentaria amanhã a taxa de juros. se.......?????

Esse tipo de emprego apenas hipotético pode ainda ser adaptado a situações passadas, como:

Ladrão teria atirado no rio a arma do crime.

Como o imperfeito do indicativo pode também ser empregado em construções condicionais (Se eu ganhasse na loteria, comprava um carro importado), pode também ser adaptado a construções de polidez:

Eu queria ver aquela blusa da vitrine.

Em todos esses casos, o principal atrator é a sociabilidade, ou seja, a intenção do falante em preservar a face diante de seu interlocutor.

Vejamos agora o emprego dos tempos do mundo comentado (presente e futuro do presente) no mundo narrado.

Esse emprego, chamado pelas gramáticas do português de presente histórico, tem o objetivo de destacar eventos passados e é o resultado de uma integração conceptual entre o tempo passado e presente por compressão. Compressão é um tipo de integração conceptual presente no nosso dia a dia. Quando dizemos, por exemplo, algo como - A cada mês que passa, esta conta de telefone está mais alta!, estamos integrando, por compressão, todas as contas de telefone anteriores em uma só, a que temos nas mãos. Dizer, como no texto citado há pouco, que - o ministro francês da Guerra, Alexande Millerand, convoca os principais industriais e lhes comunica que, dentro de dois meses, faltará munição para os canhões franceses. - traz, de maneira dramática aos nossos dias, um evento acontecido na França em 1914, comprimindo o tempo passado no tempo presente.

Esse processo é muito utilizado na mídia em títulos de matéria e em citações. Exemplos:

Hugo Chavez manifesta apoio a Khadaffi.

Tempestade de granizo destrói telhados em Florianópolis.

Montaigne diz que a morte nos livra de todas as nossas obrigações. 
No último exemplo, apesar de o filósofo francês ter escrito essa frase em 1887, em seus Ensaios, utilizamos o presente histórico para tornar essa afirmação mais vívida. Esse processo de compressão temporal acontece até mesmo em nossa conversação diária, em frases como:

Eu estava pensando em ficar em casa no Carnaval. Aí, meu primo aparece e me convida para descer para a praia.

No caso dessa metáfora temporal, o atrator é aquilo que Perelman e OlbrechtsTyteca (1988) chamam de presença, como função retórica. Segundo eles:

A presença age de uma maneira direta sobre nossa sensibilidade. É um dado psicológico que, como mostra Piaget, exerce uma ação desde o nível da percepção [...]. Assim, o que está presente à consciência adquire uma importância que a prática e a teoria da argumentação devem levar em conta. (PERELMAN; OLBRECHTS-TYTECA, 1988, p.156). ${ }^{27}$

Dizem, mais à frente:

Também uma das preocupações do orador será a de tornar presente, apenas pela magia de seu verbo, o que está efetivamente ausente e que ele considera como importante para sua argumentação, ou de valorizar, tornando-os mais presentes, elementos efetivamente oferecidos à consciência. (PERELMAN; OLBRECHTS-TYTECA, 1988, p.156). ${ }^{28}$

\section{Conclusão}

Meu objetivo, neste artigo, foi oferecer ao leitor algumas aplicações da teoria da integração conceptual (blending theory) a dados da língua portuguesa, trabalhando com a perspectiva da linguagem vista como um sistema adaptativo complexo. Acredito que essa escolha poderá render frutos também no ensino da língua, especialmente no ensino médio. Embora o modelo da integração conceptual tenha sofrido, em seu início, a partir dos trabalhos de Turner (1996) e Fauconnier e Turner (2002), críticas por aparentar ser, na avaliação de alguns linguistas, uma espécie de silver bullet ${ }^{29}$ capaz de resolver qualquer problema; nos

27 No original: "La présence agit d'une manière directe sur notre sensibilité. C'est um donné psychologique qui, comme le montre Piaget, excerce une action dès le niveau de la perception [...]. Ainsi, ce que est présent à la conscience acquiert une importance dont la pratique e la théorie de l'argumentation doivent tenir em compte."

28 No original: "Aussi l'une des préoccupations de l'orateur sera-t-elle de rendre présent, par la seule magie de son verbe, ce qui est effectivement absent, et qu'il considere comme important pour son argumentation, ou de valoriser, em les rendant plus présents, certains de éléments effectivement offerts à la conscience."

29 Bala de prata. Termo utilizado por Bache (2005), ao comentar algumas reações iniciais à teoria do blending conceptual. É uma metáfora que significa uma solução eficaz capaz de resolver todo e qualquer problema. 
dias atuais, depois de sucessivos aperfeiçoamentos, notadamente os realizados por Bache (2005) e Hougaarg (2005), vem ganhando notável respeito e confiabilidade. Como diz Schmid (2011, p.219):

No presente momento, a teoria do blending conceptual está suficientemente detalhada para permitir predições confiáveis o bastante sobre como humanos lidarão com situações compelindo-os a combinar conceitos familiares, mas não previamente relacionados em um novo conceito. ${ }^{30}$

ABREU, A. S. Conceptual integration in the description of grammatical phenomena in Brazilian Portuguese. Alfa, São Paulo, v.57, n.1, p.229-256, 2013.

- ABSTRACT: Functional grammar currently has a great acceptance in linguistics, mainly because it can enlighten grammatical facts' motivation in the structure of a text. From its emergence, the tradition of studying grammar by grammar has come to an end. Demonstrative pronouns, for instance, have begun to be viewed as efficient tools of text cohesion, used to resume terms from previous clauses. This task, however, ends up leaving an endless trail of "black boxes." How is it possible to explain the origin of demonstratives" anaphoric functioning if they are originally used to indicate things or people relative to the interlocutors' spatial position? This work aims at showing that Cognitive Linguistics arises just as an option for opening those "black boxes." This article focuses on one of its themes - the conceptual blending theory - to support this possibility. Firstly, it was necessary to integrate the cognitive model into the complexity theory, according to Bybee (2010) and Castilho (2009), who understand language as a complex adaptive system. After that, a brief updated description on the conceptual blending theory is made and its application in some grammatical facts of the Brazilian Portuguese language is suggested under the morphological and syntactic levels.

- KEYWORDS: Conceptual integration. Blending. Complexity. Portuguese grammar

\section{REFERÊNCIAS}

ABREU, A. S. Linguística cognitiva: uma visão geral e aplicada. São Paulo: Ateliê, 2010.

BACHE, C. Constraining conceptual integration theory: levels of blending and disintegration. Journal of Pragmatics, Amsterdam, v.37, p.1615-1635, 2005.

BYBEE, J. Language, usage and cognition. Cambridge: Cambridge University Press, 2010.

Sua origem vem do mito de que apenas uma bala de prata é capaz de matar um lobisomem e outros monstros semelhantes.

30 No original: "In its present state conceptual blending theory is sufficiently detailed to allow for fairly reliable prediction of how humans will deal with situations forcing them to combine familiar but previously unrelated concepts in one novel concept." 
CASTILHO, A. T. Gramática do português brasileiro. São Paulo: Contexto, 2010.

Análise multissistêmica da sentença matriz. In: PAIVA, V. L. M. O.; NASCIMENTO, M. do. (Org.). Sistemas adaptativos complexos. Belo Horizonte: Faculdade de Letras da UFMG, 2009. p.35-72.

COULSON, S. Semantic leaps: frame-shifting and conceptual blending in meaning construction. Cambridge: Cambridge University Press, 2001.

DAVIES, M.; FERREIRA, M. Corpus do Português: 45 milhões de palavras, 13001900. National Endowment for thehumanities, 2006. Disponível em: <http://www. corpusdoportugues.org>. Acesso em: 20 jan. 2011.

ELLIS, N. C.; LARSEN-FREEMAN, D. (Ed.). Language as a complex adaptive system. London: John Wiley \& Sons, 2009.

FAUCONNIER, G.; TURNER, M. The way we think. conceptual blending and the mind's hidden complexities. New York: Basic Books, 2002.

FLEISCHER, E. Caos/complexidade na interação humana. In: PAIVA, V. L. M. O.; NASCIMENTO, M. do. (Org.). Sistemas adaptativos complexos. Belo Horizonte: Faculdade de Letras da UFMG, 2009. p.73-92.

GIBBS JUNIOR, R. W. Embodiment and cognitive science. Cambridge: Cambridge University Press, 2005.

HOUGAARD, A. Conceptual disintegration and blending in interactional sequences: a discussion of new phenomena, processes vs. products, and methodology. Journal of Pragmatics, Amsterdam, v.27, p.1653-1685, 2005.

ISNENGHI, M. História da primeira guerra mundial. Tradução de Mauro Lando e Isa Mara Lando. São Paulo: Ática, 1995.

JOHNSON, N. Simply Complexity. a clear guide to complexity theory. Oxford: Oneworld Publications, 2009.

LAKOFF, G.; JOHNSON, M. Philosophy in the flesh: the embodied mind and its challenge to Western thought. New York: Basic Books, 1999.

MITCHELL, M. Complexity a guided tour. Oxford: Oxford University Press, 2009.

PAIVA, V. L. M. O.; NASCIMENTO, M. do. (Org.). Sistemas adaptativos complexos. Belo Horizonte: Faculdade de Letras da UFMG, 2009.

PERELMAN, C.; OLBRECHTS-TYTECA, L. Traité de l'argumentation: la nouvelle rhétorique. 5.ed. Bruxelles: Editions de L'Université de Bruxelles, 1988.

PERLS, F. A abordagem gestáltica e testemunha ocular da terapia. 2.ed. Tradução de José Sanz. Rio de Janeiro: Psyche, 1988. 
SCHMID, H. Conceptual blendind, relevance and novel N + N compounds. In: SCHMID, H.; HANDL, S. (Ed.). Windows to the mind: metaphor, metonymy and conceptual blending. Berlin: De Gruyter Mouton, 2011. p.218-220.

TAYLOR, R. J. Cognitive grammar. Oxford: Oxford University Press, 2003.

TURNER, M. The literary mind: the origins of thought and language. Oxford: Oxford University Press, 1996.

WEINRICH, H. Le temps: le récit e le commentaire. Paris: Seuil, 1973.

Recebido em 29 de setembro de 2011

Aprovado em 24 de novembro de 2012 